\title{
Coping Strategies being Practiced by the Breast Cancer Survivors before Receiving First Cycle of Chemotherapy
}

\author{
Deeksha Sharma ${ }^{1}$, Monika Dutta ${ }^{2}$, Sukhpal Kaur², Budhi S. Yadav ${ }^{3}$, Krishan \\ Kumar $^{4}$, Divya Dahiya ${ }^{5}$
}

'Department of Nursing Education, PGIMER, Chandigarh, India. ${ }^{2}$ Department of Nursing Education, PGIMER, Chandigarh, India. ${ }^{3}$ Department of Radiation Oncology, PGIMER Hospital, Chandigarh, India. ${ }^{4}$ Department of Psychiatry, PGIMER Hospital, Chandigarh, India. ${ }^{5}$ Department of General Surgery, PGIMER Hospital, Chandigarh, India.

\begin{abstract}
Objective: Breast cancer is the most common cancer among Indian females and chemotherapy is the most extensively used modality for these patients. Diagnosis of breast cancer is dreadful in itself and the initiation of chemotherapy causes stress and fear among patients. Breast cancer survivors (BCS) use different coping mechanisms to deal with these experiences and to handle these stressful events. The objective of this study was to assess the coping strategies being practiced by the BCS before receiving first cycle of chemotherapy. Method: This descriptive study was conducted on BCS attending Radiation Oncology and General Surgery OPD, PGIMER, Chandigarh from July 2018 to December 2019. Sixty two BCS were recruited using purposive sampling. Results: $51.7 \%$ participants were above 50 years of age, $56.5 \%$ had grade III breast cancer and $56.7 \%$ had left breast involvement. $62.9 \%$ were on neo-adjuvant chemotherapy and duration of confirmed diagnosis for $83.9 \%$ of them was less than a year. Most of the participants used positive coping strategies to overcome the stress related to diagnosis and chemotherapy. Out of the 46 coping activities participants retorted positive action for 31 coping activities whereas action was negative for 13 activities. Remaining two activities had equal number of positive and negative responses. Escape avoidance 'hoped a miracle would happen'; 'Wished that the situation would go away or somehow be over with' were used by all the participants. Though not dominant, negative coping activities were still used by the participants to deal with stressful situations. Conclusion: BCS were predominantly using positive coping activities. In order to further increase this there is a need among medical professionals to make BCS aware and discourage the use negative coping behaviors. BCS can also be nudged to adopt positive coping styles by involving family and society in the provision of care.
\end{abstract}

Keywords: Breast cancer- breast cancer survivors- coping strategies- chemotherapy

Asian Pac J Cancer Care, 6 (2), 167-173

Submission Date: 07/30/2020Ａcceptance Date: 03/20/2021

\section{Introduction}

Breast cancer is the number one cancer among Indian females and chemotherapy is most often used modality to treat breast cancer [1-2]. India is facing a challenging situation with increase in mortality due to breast cancer. Available treatment options are surgery; chemotherapy; hormonal therapy; biological therapy and radiation therapy [3]. Chemotherapy can improve prospects for long term survival but is also associated with long term toxicity including possibility of physical, emotional and cognitive impairments [4].
When an individual is diagnosed with breast cancer, one can only notice the physical effects, but the diagnosis of breast cancer has many other concealed effects, unnoticeable to other people. One such effect is the psychological effect. Breast is an important part of woman's body, whether we see it from the point of view of beauty, sexuality or motherhood [5]. Every woman has her own capabilities to deal with the challenges in her life. Many women consider it as bad phase of life and move ahead while others may become stressed and depressed.

Corresponding Author:

Dr. Monika Dutta

Department of Nursing Education, PGIMER, Chandigarh, India.

Email: monika.dutta75@gmail.com 
Factors like family involvement, social support, self belief and determination encourage patients to come out of this tragic phase and motivate to use positive coping strategies. Many myths and misconceptions are prevalent regarding chemotherapy like permanent hair loss, reoccurrence risks, and used only when the cancer is in advance stages. Chemotherapy has both direct and indirect psychological impacts. The psychologically active paraneoplastic hormones can affect the coping abilities directly whereas emotional reaction related to chemotherapy associated bodily symptoms can influence coping mechanism indirectly [6]. It is well documented in some literatures that in the face of stress and trauma people start using coping mechanisms to maintain psychological equilibrium. Coping strategies used by BCS can be positive or negative, positive use is always associated with better outcomes in terms of handling stressful situation and good QOL.

As per evidences, several factors influence the coping strategies of BCS including demographic characteristics; educational status; family and social support and psychological support [7]. Although there are many studies on how BCS overcome diagnosis by using positive and negative coping strategies. This will be the first study to show how BCS deal with chemotherapy experience after diagnosis. Therefore, the objective of this study was to assess the coping strategies practiced by BCS before receiving first cycle of chemotherapy.

\section{Materials and Methods}

\section{Study Design and Setting}

This descriptive study was conducted in Radiation Oncology and General Surgery OPD, Post Graduate Institute of Medical Education and Research (PGIMER), Chandigarh from July 2018 to December 2019. PGIMER, is one of the leading medical Institute of India. It was established in 1962 and has been functioning as an autonomous body under Ministry of Health and family welfare, Government of India since 1967 through the parliament act of institute of National importance. The source population was all BCS attending Radiation Oncology and General Surgery OPD, PGIMER Chandigarh before chemotherapy during the study period.

\section{Sample size and sampling techniques}

The total sample size was calculated on the basis of the pilot study i.e. average number of patients starting first chemotherapy cycle at Radiation Oncology and General Surgery OPD, PGIMER, Chandigarh. Purposive sampling technique was used to enroll sixty two participants who were fulfilling the preset inclusion criteria.

\section{Study Criteria}

Inclusion criteria: (1) Breast cancer patients scheduled for first cycle of chemotherapy, before or after breast surgery, (2) Patients who were able to read write and to understand Hindi language. Exclusion criteria: (1) Having previous history of cancer, (2) Patients having neurological and mental health disorders, (3) Not willing to participate.
Data collection tools and techniques

Data was collected using Interview Schedule and Folkman and Lazarus questionnaire.

1. Interview Schedule -It is divided into two parts:

A. Socio- demographic profile sheet - To obtain socio - demographic information of the participants such as name, age in years, religion, habitat, educational status, occupation, marital status, family type, number of family members, total family income (in rupees), and socio-economic status (as per modified B.G Prasad scale 2019).

B. Clinical profile sheet- To collect information pertaining to menstrual history, parity, history of truncal obesity, BMI $\left(\mathrm{Kg} / \mathrm{m}^{2}\right)$, co-morbidities, family history, laterality, stage (TNM), grade, quadrant and lymph node involvement and surgical treatment.

2. Folkman and Lazarus questionnaire to assess coping mechanisms.

The questionnaire used to assess coping mechanisms contains 46 items that is adopted from Folkman and Lazarus tool (1988). The tool contains eight major components of coping namely confrontive; distancing; self- controlling; seeking social support; accepting responsibilities; escape avoidance; plan full problem solving and positive appraisal, which further comprises of various coping activities with similar concepts. Participant's responses were assessed as Yes or No for the use of positive and negative coping strategies. Negative and uncertain responses for the given activity were categorized as unpracticed or unused responses. The response's such as 'quite a bit' and 'a great deal' were categorized as positive responses since both responses indicated that the respondent used the activities [5].

\section{Pretest}

Content validity of the tools was ensured and modifications were done after the pilot study on $10 \%$ of BCS in Radiation Oncology OPD. For flawless administration tool was written in clear and easily understandable Hindi language.

\section{Ethical consideration}

Ethical approval for the study was obtained from the Institute Ethics Committee of PGIMER, Chandigarh and complete autonomy was given to the participants in the study. After informing them about the study written informed consent was taken. Confidentiality was ensured.

\section{Data analysis}

Descriptive and inferential statistics were used to analyze the data. Calculations were carried out manually along with Microsoft excel and Statistically Package for Social Science (SPSS) program version 23. Frequencies, percentage, mean, range, $\mathrm{SD}$, were used to describe the study population in relation to different variables. Analyzed data was presented in the form of tables and figures. 


\section{Results}

\section{Socio demographic Characteristics}

Out of 62 BCS, more than half of participants $(51.7 \%)$ were above the age of 50 years and Hindu $(51 \%)$ by religion. Majority of the participants belonged to rural area $(62.9 \%)$ and were illiterate or educated up to primary level (54.8\%). Most of the participants were married (83.9\%) and $72.6 \%$ were unemployed. More than half $(54.8 \%)$ of the participants were from nuclear families. Around half $(48.4 \%)$ belonged to the middle and lower middle class of socio-economic status (as per modified B.G Prasad scale 2018) (Table1).

\section{Clinical Characteristics}

Majority of the participants $(74.2 \%)$ had a history of irregular menstrual cycle. Most of the BCS were multiparous (98.4\%). Only $14.5 \%$ had truncal obesity and $32.3 \%$ participants were overweight. Co-morbidities were present in $30.6 \%$ of the participants and hypertension was the most common co-morbidity found among BCS i.e. $89.4 \%$. Only $4.8 \%$ of BCS had a positive family history of breast cancer. More than half $(56.5 \%)$ of the participants had left side breast involvement.53.2\% of the participants had early stage as per TNM classification. Around (58\%) of the BCS had grade III breast cancer. Majority of the BCS had upper outer quadrant (79\%), and lymph node $(72.6 \%)$ involvement (Table 2).

\section{Treatment profile}

More than half $(62.9 \%)$ of the BCS were on neo-adjuvant chemotherapy (Table 3 ). Only chemotherapy as a treatment modality was used in $56.5 \%$ of BCS and $53.2 \%$ participants were receiving anthracyclins drugs.

\section{Surgical intervention profile}

Surgical interventions were done in $48.3 \%$ of participants. Majority (27.4\%) of them had undergone surgical procedure i.e. TMAC. None of the participants had reported any complication associated with surgery (Figure1).

\section{Coping Mechanisms}

This questionnaire consists of 46 items designed to measure eight different coping styles namely confrontive;

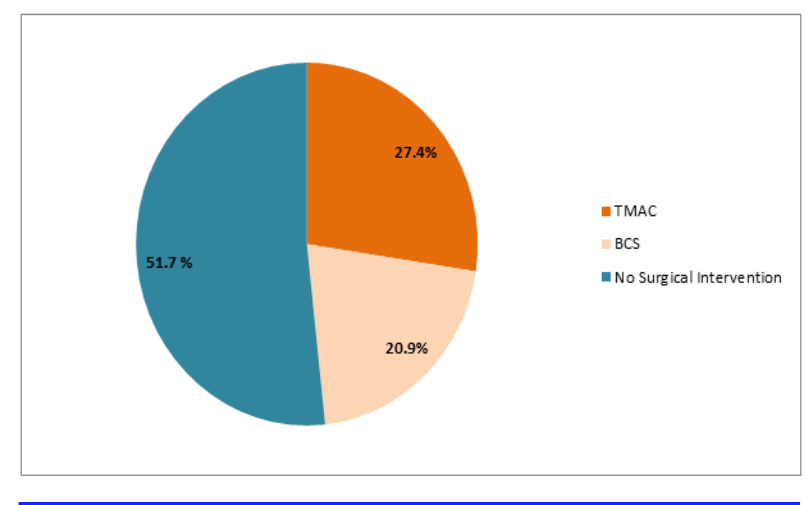

Figure 1. Surgical Intervention Profile of Breast Cancer Survivors $(\mathrm{N}=62)$.
Table 1. Socio-demographic Characteristics of Participants $(\mathrm{N}=62)$.

\begin{tabular}{|c|c|}
\hline Socio-demographic characteristics & $f(\%)$ \\
\hline \multicolumn{2}{|l|}{ Age (yrs) } \\
\hline Less than 50 & $30(48.3)$ \\
\hline More than 50 & $32(51.7)$ \\
\hline \multicolumn{2}{|l|}{ Religion } \\
\hline Hindu & $51(82.3)$ \\
\hline Sikh & $11(17.7)$ \\
\hline \multicolumn{2}{|l|}{ Habitat } \\
\hline Rural & $39(62.9)$ \\
\hline Urban & $23(37.1)$ \\
\hline \multicolumn{2}{|l|}{ Educational Status } \\
\hline Illiterate & $17(27.4)$ \\
\hline Primary & $17(27.4)$ \\
\hline Secondary & $12(19.4)$ \\
\hline Graduate or Above & $16(25.8)$ \\
\hline \multicolumn{2}{|l|}{ Occupation } \\
\hline Professional & $12(19.4)$ \\
\hline Skilled worker & $5(8.1)$ \\
\hline Unemployed & $45(72.6)$ \\
\hline \multicolumn{2}{|l|}{ Marital Status } \\
\hline Married & $52(83.9)$ \\
\hline Widow & $10(16.1)$ \\
\hline \multicolumn{2}{|l|}{ Family type } \\
\hline Joint & $28(45.2)$ \\
\hline Nuclear & $34(54.8)$ \\
\hline \multicolumn{2}{|l|}{ Numbers of family members } \\
\hline 4-Jan & $34(54.8)$ \\
\hline 9-May & $25(40.3)$ \\
\hline 14-Oct & $3(4.8)$ \\
\hline \multicolumn{2}{|l|}{ Total family income (in Rupees) } \\
\hline $1000-9999$ & $28(45.2)$ \\
\hline 10000- 29999 & $18(29.1)$ \\
\hline 30000- 49999 & $6(9.6)$ \\
\hline 50000 and above & $10(16.1)$ \\
\hline
\end{tabular}

Socio- Economic Status (As per modified B.G Prasad Scale 2018)

Upper Class (>6754)

Upper middle Class (3287-6573)

Middle class (1972-3286)

Lower middle class (986-1971)

Lower class $(<985)$ $8(12.9)$

Mean \pm SD (Range) $50.11 \pm 10.53$ (28-75)

distancing; self- controlling; seeking social support; accepting responsibility; escape avoidance; plan full problem solving and positive appraisal. Out of these, distancing and escape avoidance were the only negative coping styles whereas others were positive. It is evident from the (Table 4 ) that out of 46 coping activities participants responded positively for 31 whereas negative 
Table 2. Clinical Profile of Participants Receiving Chemotherapy for Breast Cancer $(\mathrm{N}=62)$.

\begin{tabular}{|c|c|}
\hline Variables & $f(\%)$ \\
\hline \multicolumn{2}{|l|}{ Menstrual history } \\
\hline Regular & $16(25.8)$ \\
\hline Irregular & $46(74.2)$ \\
\hline \multicolumn{2}{|l|}{ Parity } \\
\hline Nulliparous & $1(1.6)$ \\
\hline Multiparous & $61(98.4)$ \\
\hline \multicolumn{2}{|l|}{ Truncal obesity } \\
\hline Present & $9(14.5)$ \\
\hline Absent & $53(85.5)$ \\
\hline \multicolumn{2}{|l|}{$\mathrm{BMI}\left(\mathrm{Kg} / \mathrm{m}^{2}\right)$} \\
\hline Normal & $26(41.9)$ \\
\hline Overweight & $20(32.3)$ \\
\hline Obesity Class-I & $11(17.7)$ \\
\hline Obesity Class-II & $5(8.1)$ \\
\hline \multicolumn{2}{|l|}{ Co- morbidities $(\mathrm{n}=19)$} \\
\hline Hypertension & $17(89.4)$ \\
\hline Diabetes mellitus & $1(5.2)$ \\
\hline Thyroid disorders & $1(5.2)$ \\
\hline \multicolumn{2}{|l|}{ Family history } \\
\hline Yes & $3(4.8)$ \\
\hline \multicolumn{2}{|l|}{ Laterality } \\
\hline Ca left breast & $35(56.5)$ \\
\hline Ca right breast & $26(41.9)$ \\
\hline Ca bilateral breast & $1(1.6)$ \\
\hline \multicolumn{2}{|l|}{ Stage (TNM) } \\
\hline Early & $33(53.2)$ \\
\hline Locally advanced & $25(40.3)$ \\
\hline Metastatic & $4(6.5)$ \\
\hline \multicolumn{2}{|l|}{ Grade } \\
\hline I & $5(8.1)$ \\
\hline II & $21(33.9)$ \\
\hline III & $36(58.0)$ \\
\hline \multicolumn{2}{|l|}{ Quadrant involved } \\
\hline Upper outer quadrant & $49(79)$ \\
\hline Upper inner & $4(6.5)$ \\
\hline Lower outer & $4(6.5)$ \\
\hline Lower inner & $2(3.2)$ \\
\hline More than one & $3(4.8)$ \\
\hline \multicolumn{2}{|l|}{ Lymph nodes } \\
\hline Yes & $45(72.6)$ \\
\hline No & $17(27.4)$ \\
\hline
\end{tabular}

response was noticed for 13 activities. For the remaining two activities half of the participants responded in a positive way whereas remaining half had a negative response. Escape avoidance is one of the major predictor of negative coping among all the coping strategies, under its subparts "hoped a miracle would happen"; "Wished that the situation would go away or somehow
Table 3. Treatment Profile of Participants Receiving Chemotherapy for Breast Cancer $(\mathrm{N}=62)$.

\begin{tabular}{lc}
\hline Variables & $\mathrm{f}(\%)$ \\
\hline Type of Chemotherapy & $23(37.1)$ \\
Adjuvant & $39(62.9)$ \\
Neo- Adjuvant & \\
Treatment plan & $35(56.5)$ \\
Chemotherapy only & $8(12.9)$ \\
Chemotherapy+ Radiotherapy & $18(29)$ \\
Surgery + Chemotherapy & $1(1.6)$ \\
Chemotherapy +Surgery+ Hormonal therapy & \\
Chemotherapeutic drugs & $47(75.8)$ \\
Anthracyclin & $15(24.2)$ \\
Anthracyclin+ Taxane &
\end{tabular}

be over with" were used by all the participants in this study. Although the negative coping activities were not predominant but were still used by the participants up to some extent.

\section{Discussion}

The results of this study highlighted that the use of positive coping strategies was predominant among BCS to overcome the stress and fear related to diagnosis and chemotherapy. In present study, out of the 46 coping activities participants retorted positive action for 31 whereas it was negative for 13 activities. Remaining two activities had equal number of positive and negative responses. Thus, in order to discourage the use of negative coping behaviors efforts are required on behalf of nursing professionals to make their patients aware about negative coping activities and at the same time encouraging them to use more of the positive coping strategies. Role of family and society cannot be ignored during this stressful period of life so both the family as well as society can be involved by nurses in nudging the BCS towards adopting positive coping styles.

Escape avoidance is one of the major predictor of negative coping among all the coping strategies. Out of its nine components participants showed a positive reaction towards six of them. It was astonishing that all the participants resorted to the negative strategies "hoped that a miracle would happen" and "wished that the situation would go away or somehow be over with" as a measure to cope. These findings were contrary to another study where wishful thinking was the least commonly used coping strategy six months after the diagnosis [8]. 88.7\% participants of current study "accepted the situation, since nothing could be done". This is consistent with the results reported by Chen et al. [9] where acceptance was one of the most common types of coping reactions and it can be directly linked to lower distress.

Helplessness and hopelessness are two factors responsible for the use of escape avoidance coping style by the patients instead of facing the situation. Therefore, escape-avoidance coping style strongly predicts a worse 
Table 4. Distribution of BCS on the Basis of Coping Activities Using Folkman and Lazarous Scale (N=62)

\begin{tabular}{|c|c|c|c|}
\hline \multirow[t]{2}{*}{ Coping activities } & & \multicolumn{2}{|c|}{ Response } \\
\hline & & Yes N $(\%)$ & No $N(\%)$ \\
\hline \multirow[t]{3}{*}{ Confrontive } & I did something which I didn't think would work, but at least I was doing something & $16(25.8)$ & $46(74.2)$ \\
\hline & I let my feelings out somehow & $57(91.9)$ & $5(8.1)$ \\
\hline & Stood my ground and fought for what I wanted & $55(88.7)$ & $7(11.3)$ \\
\hline \multirow[t]{6}{*}{ Distancing } & Turned to work or substitute activity to take my mind off things & $8(12.9)$ & $54(87.1)$ \\
\hline & Went along with fate; sometimes I just have bad luck & $15(24.2)$ & $47(75.8)$ \\
\hline & Went on as if nothing had happened & $8(12.9)$ & $54(87.1)$ \\
\hline & Looked for the silver lining, so to speak; tried to look on the bright side of things & $23(37.1)$ & $39(62.9)$ \\
\hline & Didn't let it get to me; refused to think too much about it & $25(40.3)$ & $37(59.7)$ \\
\hline & Made light of the situation; refused to get too serious about it & $17(27.4)$ & $45(72.6)$ \\
\hline \multirow[t]{4}{*}{ Self-controlling } & Tried not to burn my bridges, but leave things open somewhat & $31(50)$ & $31(50)$ \\
\hline & I tried to keep my feelings to myself & $43(69.4)$ & $19(30.6)$ \\
\hline & I tried not to act too hastily or follow my first hunch & $41(66.1)$ & $21(33.9)$ \\
\hline & I tried to keep my feelings from interfering with other things too much & $61(98.4)$ & $1(1.6)$ \\
\hline \multirow[t]{6}{*}{ Seeking social support } & Talked to someone to find out more about the situation & $57(91.9)$ & $5(8.1)$ \\
\hline & Accepted sympathy and understanding from someone & $51(82.3)$ & $11(17.7)$ \\
\hline & I got professional help & $56(90.3)$ & $6(9.7)$ \\
\hline & Talked to someone who could do something concrete about the problem & $56(90.3)$ & $6(9.7)$ \\
\hline & I asked a relative or friend I respected for advice & $25(40.3)$ & $37(59.7)$ \\
\hline & Talked to someone about how I was feeling & $59(95.2)$ & $3(4.8)$ \\
\hline \multirow[t]{3}{*}{ Accepting responsibilities } & Criticized or lectured myself & $7(11.3)$ & $55(88.7)$ \\
\hline & I told myself things that helped me to feel better & $23(37.1)$ & $39(62.9)$ \\
\hline & I made a promise to myself that things would be different next time & $15(24.2)$ & $47(75.8)$ \\
\hline \multirow[t]{5}{*}{ Positive appraisal } & Changed or grew as a person in a good way & $14(22.6)$ & $48(77.4)$ \\
\hline & I came out of the experience better than when I went in & $56(90.3)$ & $6(9.7)$ \\
\hline & Found new faith & $55(88.7)$ & $7(11.3)$ \\
\hline & Rediscovered what is important in life & $10(16.1)$ & $52(83.9)$ \\
\hline & I prayed & $55(88.7)$ & $7(11.3)$ \\
\hline \multirow{9}{*}{$\begin{array}{l}\text { Escape avoidance coping } \\
\text { activities }\end{array}$} & Hoped a miracle would happen & $62(100)$ & - \\
\hline & Slept more than usual & $14(22.6)$ & $48(77.4)$ \\
\hline & Got away from it for a while; tried to rest or take a vacation. & $10(16.1)$ & $52(83.9)$ \\
\hline & $\begin{array}{l}\text { Tried to make myself feel better by eating, drinking, smoking, using drugs or } \\
\text { medication, etc }\end{array}$ & - & $62(100)$ \\
\hline & Avoided being with people in general & $15(24.2)$ & $47(75.8)$ \\
\hline & Took it out on other people & $6(9.7)$ & $56(90.3)$ \\
\hline & Refused to believe that it had happened & $7(11.3)$ & $55(88.7)$ \\
\hline & Accepted it, since nothing could be done & $55(88.7)$ & $7(11.3)$ \\
\hline & Wished that the situation would go away or somehow be over with & $62(100)$ & - \\
\hline \multirow[t]{10}{*}{ Planful problem solving } & Just concentrated on what I had to do next - the next step & $56(90.3)$ & $6(9.7)$ \\
\hline & I tried to analyze the problem in order to understand it better & $60(96.8)$ & $2(3.2)$ \\
\hline & I felt that time would make a difference - the only thing to do was to wait & $56(90.3)$ & $6(9.7)$ \\
\hline & Bargained or compromised to get something positive from the situation & $7(11.3)$ & $55(88.7)$ \\
\hline & Changed something so things would turn out all right & $56(90.3)$ & $6(9.7)$ \\
\hline & I knew what had to be done, so I doubled my efforts to make things work & $7(11.3)$ & $55(88.7)$ \\
\hline & Came up with a couple of different solutions to the problem & $51(82.3)$ & $11(17.7)$ \\
\hline & I prepared myself for the worst & $60(96.8)$ & $2(3.2)$ \\
\hline & I went over in my mind what I would say or do & $31(50)$ & $31(50)$ \\
\hline & I jogged or exercised & $13(21)$ & $49(79)$ \\
\hline
\end{tabular}


psychological well-being [5]. It has been recommended that medical professionals should be well versed in identifying the coping styles and treat accordingly [10]. It is good to see that in the current study out of nine coping activities under escape avoidance coping style, only three were used by the participants and majority of the BCS didn't use six negative coping activities which reflects a good state of their psychological health. Counseling sessions can be provided including information regarding coping strategies to make them aware about positive coping styles and discourage the use of negative coping activities.

Seeking social support is one of the major components of positive coping strategies. The result of the current study showed that majority of the participants took positive initiative for seeking social support. This reflects their readiness to seek help from family, friends, society and health care professionals which can contribute towards better treatment outcome. This is in agreement with the study where instead of religion and spirituality, social support has more significant association in coping [11]. Therefore, in order to make the patient strong at the emotional level, it is imperative that family, society and professionals participate actively in patient care. Therefore seeking social support can be an important aspect to improve QOL and deal with present situation by effective use of coping style.

Planful problem solving is another part of positive coping strategies. Out of ten coping activities under this component, participants responded positively for six activities and in a negative way for three activities. For 'I went over in my mind what I would say or do' equal number of participants responded in positive and negative way. The more effectively patients use planful problem solving, the more it helps them to cope positively with the situation. By using planful problem solving as a coping strategy a person can focus their efforts on planning and positive reframing that would help them to take action towards resolving their problems and help them better adjust to chemotherapy experience [12]. It has been documented that planful problem solving was frequently used coping strategy by breast cancer patients who were anxious [12].

Exercise is one of the major component of planful problem solving activities [5]. In the present study 79\% of the participants did not jog or exercise. These findings were contrary to a study where physical exercise was identified as one of the coping strategies among cancer patients [13]. Exercises are required for healthy behavior change in patients in terms of adopting positive strategies to deal with the situation [14-15]. So keeping in mind the current study findings a need was felt to guide the BCS. They were encouraged and informed about the benefits of exercise in this traumatic phase of illness.

Positive appraisal is one of the major positive coping strategies, which has a greater influence on patient's coping style. In the present study majority of participants 'prayed' (88.7\%), 'found new faith' $(88.7 \%)$ and 'came out of the experience better than went in' $(90.3 \%)$. Religious coping is one of the alternatives for making psychological adjustment [16]. Prayer and other religious practices helped the current study subjects to calm down mentally and at the same time provided courage to deal with the challenges in life. These results are consistent with the study conducted by Ahmad et al [17] where majority of participants used religious faith and practices as a coping style.

Self controlling, a positive coping strategy, was used by majority of participants to cope with the stressful situations. $98.4 \%$ of participants 'tried to keep their feelings from interfering with other things too much'. Therefore by keeping themselves busy or distracted in other activities they were able to avoid thinking too much about their problem. That's why self controlling is a good way to cope with this situation. These findings are supported by a study conducted by Burger [18] where self controlling as a coping strategy can positively influence the outcome of stressful event.

In the present study, majority of participants responded in a positive way to cope by confronting the situation. $91.9 \%$ of participants responded to positive coping strategies 'let their feeling out somehow' and $88.7 \%$ 'stood their ground and fought for what they wanted'. This suggested that acceptance of a situation is very important. Once the acceptance is there then only a person starts looking for alternatives, contrary to this chances of adopting negative coping styles are more when one runs away from the situation. Similar findings were also reported by Amare et al [5], where most of BCS had used confrontive as a coping strategy to cope up with breast cancer.

Distancing represents a major part of negative coping strategies. In the present study, for this component majority of the participants responded in a positive way. Similar findings were reported in a study by Amare et al [5] where distancing was the least used negative coping strategy. Distancing can be one of the reasons to have negative opinion about chemotherapy and thus delaying the early interventions. This highlights the importance of encouraging patients for the use of positive coping styles. The encouraging attitude of health care professionals can facilitate the process of problem solving rather than distancing from the actual scenario.

Accepting responsibilities is one of the positive coping styles. In the present study, majority of the participants responded negatively for this component. Wonghongkul et al. [19] supported the current findings that 'acceptance of responsibilities' was least used coping strategy among BCS.

In conclusion, the present study revealed that the use of positive coping activities was predominant among BCS to overcome the stress and fear related to diagnosis and chemotherapy. In spite of being lesser in number, negative coping strategies were still used by some of the participants to deal with stressful situations. After completion of the study all participants using negative coping strategies were contacted and counseled to encourage the use of positive coping styles. 


\section{Limitations}

Limited data collection period and lesser number of patients, meeting our inclusion criteria, visiting OPDs per day resulted in a small sample size for this study. This sample size cannot capture the diversity of the country. Thus there is a scope for the future studies being done with a larger and more diverse sample size.

\section{Acknowledgements}

The authors would like to thank Ms. Maninderdeep Kaur (Nursing Tutor, PGIMER Chandigarh), all the participants involved in this study for sharing their experiences with us for the contribution of a better future. We conclude our acknowledgment and appreciate all those who have contributed to this study directly or indirectly.

\section{Author's Contribution}

Deeksha Sharma conceptualized and prepared the first draft, collected and analyzed the data and prepared the final paper. Monika Dutta reviewed and corrected the drafts and provided guidance to better shape the study. Sukhpal Kaur reviewed and corrected the drafts. Budhi Singh Yadav helped in assignment of patients, reviewed and corrected the drafts. Krishan Kumar contributed in finalizing the tools. Divya Dahiya supported clinically.

\section{Statement conflicts of Interest}

The authors declare no conflict of interest.

\section{Source of Funding}

The authors did not receive any external sources of funding of this study.

\section{References}

1. Malvia S, Bagadi SA, Dubey US, Saxena S. Epidemiology of breast cancer in Indian women. Asia-Pacific Journal of Clinical Oncology. 201702 09;13(4):289-295. https://doi. org/10.1111/ajco.12661

2. Mayo Clinic- Chemotherapy [Internet]. 2019 [cited 2019 Oct 22]. Available from: https://www.mayoclinic.org/testsprocedures/chemotherapy/about/pac-20385033.

3. CDC. How Is Breast Cancer Treated? [Internet]. 2018[cited 2019 Oct 17] . Available from: https://www.cdc.gov/cancer/ breast/basic_info/treatment.

4. Moore HCF. An overview of Chemotherapy-related Cognitive Dysfunction, or "Chemobrain". Oncol Williston Park N.Y. 2014 Sep;28(9):797-804.

5. Amare M. Perceptions and Coping Mechanisms Experienced by Ethiopian Breast Cancer Patients. International Journal of Pharmaceutical Sciences and Research. 2016;7(04):8.

6. Parkin D. Cancer in developing countries :Cancer Surveys. A Cancer Journal for Clinicians. 1994;19(20):519-61.

7. Al-Azri M, Al-Awisi H, Al-Moundhri M. Coping With a Diagnosis of Breast Cancer-Literature Review and Implications for Developing Countries. The Breast Journal. 2009 Nov;15(6):615-622. https://doi.org/10.1111/j.15244741.2009.00812.x

8. Sajadian A, RajiLahiji M, Motaharinasab A, Kazemnejad Eklily A, Haghighat S. Breast Cancer Coping Strategies after Diagnosis: A Six-month Follow-up. Multidisciplinary
Cancer Investigation. 2017 Nov 10;1(4):12-16. https://doi. org/10.21859/mci-01042

9. Chen S, Liu J, Li Z, Su Y. The process of accepting breast cancer among Chinese women: A grounded theory study. European Journal of Oncology Nursing. 2017 06;28:77-85. https://doi.org/10.1016/j.ejon.2017.03.005

10. Larsson J, Sandelin K, Forsberg C. Health-Related Quality of Life and Healthcare Experiences in Breast Cancer Patients in a Study of Swedish Women. Cancer Nursing. 2010 03;33(2):164-170. https://doi.org/10.1097/ ncc.0b013e3181bb0d05

11. Sohail MM, Mahmood QK, Sher F, Saud M, Mas'udah S, Ida R. Coping Through Religiosity, Spirituality and Social Support Among Muslim Chronic Hepatitis Patients. Journal of Religion and Health. 201909 16;59(6):3126-3140. https:// doi.org/10.1007/s10943-019-00909-4

12. Tuncay T, Musabak I, Gok D, Kutlu M. The relationship between anxiety, coping strategies and characteristics of patients with diabetes. Health and Quality of Life Outcomes. 2008;6(1):79. https://doi.org/10.1186/1477-7525-6-79

13. Snöbohm C, Heiwe S. Stressors, Coping and Coping Strategies Among Young Adults with Cancer. World J Psycho-Soc Oncol [Internet]. 2013 Nov 20;2(3);15-28. Available from: http://www.npplweb.com/wjpso/fulltext/2/3.

14. Petticrew M. Influence of psychological coping on survival and recurrence in people with cancer: systematic review. BMJ. 2002 Nov 09;325(7372):1066-1066. https://doi. org/10.1136/bmj.325.7372.1066

15. Haas BK. Fatigue, Self-efficacy, Physical Activity, and Quality of Life in Women With Breast Cancer. Cancer Nursing. 2011 07;34(4):322-334. https://doi.org/10.1097/ ncc.0b013e3181f9a300

16. Hebert R, Zdaniuk B, Schulz R, Scheier M. Positive and Negative Religious Coping and Well-Being in Women with Breast Cancer. Journal of Palliative Medicine. 2009 06;12(6):537-545. https://doi.org/10.1089/jpm.2008.0250

17. Ahmad F, binti Muhammad M, Abdullah AA. Religion and Spirituality in Coping with Advanced Breast Cancer: Perspectives from Malaysian Muslim Women. Journal of Religion and Health. 2010 Oct 06;50(1):36-45. https://doi. org/10.1007/s10943-010-9401-4

18. Burger J. Negative Reactions to Increases in Perceived Personal Control. J Pers Soc Psychol. 1989;56:246-56.

19. Wonghongkul T, Moore SM, Musil C, Schneider S, Deimling G. The Influence of Uncertainty in Illness, Stress Appraisal, and Hope on Coping in Survivors of Breast Cancer. Cancer Nursing. 2000 Dec;23(6):422-429. https:// doi.org/10.1097/00002820-200012000-00004

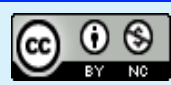

This work is licensed under a Creative Commons AttributionNon Commercial 4.0 International License. 